\title{
ETIČKO-PRAVNE SPOZNAJE PACIJENTICA O INFORMIRANOM PRISTANKU KOD OPERATIVNIH ZAHVATA GINEKOLOŠKIH PACIJENTICA
}

\author{
Olivera Perić ${ }^{1,}$ Vajdana Tomić ${ }^{1}$, Dejan Tirić $^{1}$, Ivona Margeta ${ }^{2}$ \\ ${ }^{1}$ Klinika za ginekologiju i porodništvo, Sveučilišna klinička bolnica Mostar, 88000 Mostar, Bosna i Hercegovina \\ ${ }^{2}$ Transfuzijski centar, Sveučilišna klinička bolnica Mostar, 88000 Mostar, Bosna i Hercegovina \\ Rad je primljen 22.03.2019. Rad je recenziran 01.04.2019. Rad je prihvaćen 09.05.2019.
}

\section{SAŽETAK}

UVOD: Pribavljanje pisanog informiranog pristanka za operativni zahvat je etički postulat i pravna obveza definirana zakonskim propisima u Federaciji Bosne i Hercegovine.

CILJ ISTRAŽIVANJA: Osnovni cilj istraživanja bio je procijeniti znanja o informiranom pristanku za operativni zahvat kod ginekoloških pacijentica te utvrditi postoje li razlike u znanju o informiranom pristanku za operativni zahvat pacijentica u odnosu na sociodemografska i ginekološko opstetrička obilježja

ISPITANICE I METODE: Istraživanje je obuhvatilo 235 pacijentica koje su imale operativni zahvat u Klinici za ginekologiju i porodništvo Sveučilišne kliničke bolnice Mostar. Provedeno je pomoću anonimnog anketnog upitnika posebno dizajniranog za ove potrebe. Prema stupnju hitnosti operativnog zahvata ispitivale su se pacijentice koje su imale planirani operativni zahvat $(\mathrm{n}=145)$ i pacijentice koje su imale hitan operativni zahvat $(\mathrm{n}=90)$.

REZULTATI: Sve pacijentice su bile punoljetne osobe u rasponu od 18 do 86 godina, prosječna dob pacijentica iznosila je 34 godine. Dobro znanje pacijentice su pokazale u odnosu na spoznaju da je potpisivanje pristanka obveza definirana zakonom (74,5\%), te da ukoliko nisu u mogućnosti potpisati pristanak, to može učiniti član uže obitelji $(82,1 \%)$. Slabo su znale kako su dužne potpisati izjavu o odbijanju, ukoliko odbiju predloženi medicinski zahvat $(65,1 \%)$. Nedovoljno znanje pokazale su u odnosu na pravo naknade $(28,1 \%)$, pravo na promjenu mišljenja nakon potpisivanja pristanka $(30,2 \%)$, te da se neće operirati ukoliko odbiju potpisati pristanak, pa čak i ako bi mogle umrijeti $(29,4 \%)$.

ZAKLJUČAK: Pacijenti su slabo upoznati s pravom na informirani pristanak što upućuje da je proces pristanka sveden na puku formalnost.

Ključne riječi: pisani pristanak, planirani operativni zahvat, hitni operativni zahvat

Kontakt za razmjenu informacija: Olivera Perić

E-mail: olivera.peric@fzs.sum.ba

\section{UVOD}

Informirani pristanak za medicinski zahvat predstavlja kamen temeljac moderne medicine. Jedna od definicija informiranog pristanka glasi da je informirani pristanak ili obaviješteni pristanak ili informirana suglasnost pojam za proces kojim podrobno obaviješteni pacijent daje pristanak na provođenje predloženog medicinskog postupka očitujući svoju volju slobodno i bez prisile $(1,2)$. Povijesno gledano, doktrina informiranog pristanka razvijala se postupno kroz pravnu, medicinsku i etičku dimenziju.

Iz pravne perspektive, informirani pristanak je jedno od temeljnih prava i sloboda pacijenta. Kako 
bi pristanak zadobio pravnu valjanost proces informiranja treba biti proveden, a to znači odvijanje dijaloga između pacijenta i liječnika u kojem pacijent ima prilike postavljati pitanja i čuti sva objašnjenja na temelju kojih će donijeti odluku i dati pristanak (3). Etički gledano, informirani pristanak se temelji se na zaštiti tjelesnog integriteta svakog pojedinca i slobodnom izražavanju volje o tome da li će se podvrći liječenju ili ne (2). Značenje informiranog pristanka s medicinskog aspekta otvara mogućnost za suradnju liječnika i pacijenta u pogledu utvrđivanja bolesti i odabira odgovarajućeg tretmana (4).

U Federaciji Bosne i Hercegovine 2010. donesen je Zakon o pravima, obvezama i odgovornostima pacijenta u kojem je institut informiranog pristanka razrađen od 10. do 24. članka (5). Prema tom zakonu, obvezan je pristanak potpuno informiranog pacijenta prije bilo kakvog dijagnostičkog i operativnog postupka. I drugi zakonski propisi ukazuju kako svaki operativni zahvat mora imati pismenu suglasnost onog na koga se odnosi (6). Pri tome, glavna je obveza liječnika vezana za obavljanje samog zahvata, ali ništa manji značaj nemaju obveze informiranja, pribavljanja pristanka i poslijeoperacijskog postupanja (7). Činjenica je kako operativni zahvat može imati veći ili manji rizik za pacijenta nad kojim se obavlja. Ipak, u mnogim slučajevima operacija je jedini način liječenja i krajnji cilj je rizik svesti na najmanju moguću mjeru. Odluka o operativnom zahvatu ne smije biti prepuštena samo liječnicima, obveza je uključiti i samog pacijenta koji je potpuno, temeljito i istinito informiran o svom stanju.

U svakodnevnoj kliničkoj praksi to nije uvijek jednostavno. Zakonski tražena potpuna informiranost pacijenta te zakonska obveza dobivanja pristanka za operativni zahvat predstavlja znatan problem. Izvjesno je da je ograničavajući faktor paternalizam koji je duboko ukorijenjen u našem društvu. Zato nije ni čudo što većina pacijenata pristane na operativni zahvat, iako procedura informiranog pristanka nije valjano provedena. Svoju autorizaciju pristanka na operativni zahvat najčešće daju medicinskoj sestri koja ih obično ponudi s drugim formularima kod prijema u bolnicu (8). Dakle u kliničkoj praksi postoji proturječje između položaja pacijenata reguliranog zakonskim propisima i stvarnog položaja pacijenata.

Osnovni cilj istraživanja bio je procijeniti znanja o informiranom pristanku za operativni zahvat kod ginekoloških pacijentica te utvrditi postoje li razlike u odnosu na sociodemografska i ginekološko opstetrička obilježja.

\section{ISPITANICE I METODE}

$\mathrm{U}$ svrhu ispitivanja informiranog pristanka za operativni zahvat ispitivale su se prema stupnju hitnosti operativnogzahvata dvije skupine ispitanica:pacijentice koje su imale planirani operativni zahvat i pacijentice koje su imale hitan operativni zahvat. Istraživanje se provodilo u razdoblju od šest mjeseci ( 1.03 . do 30.09.2011.) u Klinici za ginekologiju i porodništvo Sveučilišne kliničke bolnice Mostar kojemu gravitira stanovništvo sa šireg područja Hercegovine. Etičko povjerenstvo Medicinskog fakulteta u Mostaru i Etičko povjerenstvo Sveučilišne kliničke bolnice Mostar ocijenilo je istraživanje etički prihvatljivim. Pacijentice koje su pristale sudjelovati u istraživanju popunjavale su anonimne upitnike u razdoblju od dva do četiri tjedna nakon operacije. Upitnik je razvijen na temelju ranije korištenih instrumenata, nadopunjenih specifičnim pitanjima u skladu s postojećom zakonskom regulativom o informiranom pristanku u Federaciji Bosne i Hercegovine $(5,9)$. Anonimni upitnik je sadržavao dvije skupine pitanja. Sociodemografska i ginekološko opsterička skupina pitanja sastojala se od 12 pitanja otvorenog i zatvorenog tipa. Pitanja su sadržavala podatke o spolu, dobi, obrazovanju, zaposlenosti, ekonomskom statusu, mjestu boravka, dok je ginekološko - opstetrička skupina pitanja sadržavala podatke o dosadašnjim operativnim zahvatima, operativnim zahvatima na maternici, broju poroda, duljini ležanja u bolnici kao i o hitnosti operativnog zahvata. Skupina pitanja za ispitivanje znanja pacijenata o informiranom pristanku za operativni zahvat sastojala se od 10 pitanja. Sadržavala je šest pitanja koja su se odnosila na znanje o informiranom pristanku za operativni zahvat, kao i četiri pitanja o razumijevanju koncepta potpisanog obrasca pristanka. $\mathrm{Za}$ 
procjenu znanja o informiranom pristanku za operativni zahvat točni odgovori su se zbrajali. Ocjena se mjerila unaprijed određenim apsolutnim kriterijem tako da je do $60 \%$ točno danih odgovora za ispitivanje znanja ocijenjeno nedovoljnim znanjem, 61-70 \% točnih odgovora je ocijenjeno slabim znanjem, 71-80 \% točnih odgovora ocijenilo se kao dobro znanje, 81-90 \% točnih odgovora ocijenilo se kao vrlo dobro znanje, a iznad $90 \%$ točnih odgovora smatrano je izvrsnim znanjem (10).

\section{STATISTIČKA ANALIZA}

Normalnost distribucije kontinuiranih varijabli testirana je Kolmogorov-Smirnovljevim testom, a za prikaz srednje vrijednosti i mjere raspršenja koristila se aritmetička sredina i standardna devijacija. Razlike između varijabli testirane su Studentovim t-testom i ANOVA-om, a korelacija Pearsonovim koeficijentom korelacije. U kontinuiranim varijablama čija je raspodjela značajno odstupala od normalne za prikaz srednje vrijednosti i mjere raspršenja koristio se medijan i interkvartilni raspon. $\mathrm{Za}$ analizu nominalnih varijabli korišten je $\chi^{2}$ test, a pri manjku očekivane frekvencije Fisherov egzaktni test. Mogućnost pogrješke prihvatila se pri $\alpha<0,05$ te su razlike između skupina bile prihvaćene kao statistički značajne za $\mathrm{p}<0,05$.

\section{REZULTATI}

Tijekom šest mjeseci koliko se provodilo ovo istraživanje analizirani su anketni upitnici od ukupno 235 (54,5\%) pacijentica (90 hitnih i 145 planiranih operacija). Sve pacijentice su bile punoljetne osobe u rasponu od 18 do 86 godina, dok je prosječna dob pacijentica iznosila 34 godine. Većinom su imale srednju stručnu spremu 139 (59,1\%), i bile zaposlene 123 (52,3 \%). Izjavile su kako im je ekonomski status bio većinom prosječan 203 (86,4\%). Gotovo sve su bile u bračnoj zajednici $218(92,8 \%)$, i naseljene u urbanim mjestima 133 (56,6 \%). Nije postojala značajna razlika između pacijentica koje su ranije bile podvrgnute nekom operativnom zahvatu
$105(44,7 \%)$ i onih koji u svojoj povijesti nisu imale operativni zahvat bilo koje vrste 130 (55,3\%). Većina pacijentica nije imala ranije operativne zahvate na maternici 184 (78,3\%). Njih 145 (61\%) navelo je da su imale planirani operativni zahvat, dok je duljina ležanja u bolnici bila između 5 i 10 dana 182 (77,4\%).

Vidljivo je iz slike 1. da su pacijentice većinom iskazale nedovoljno poznavanje informiranog pristanka (Slika 1).

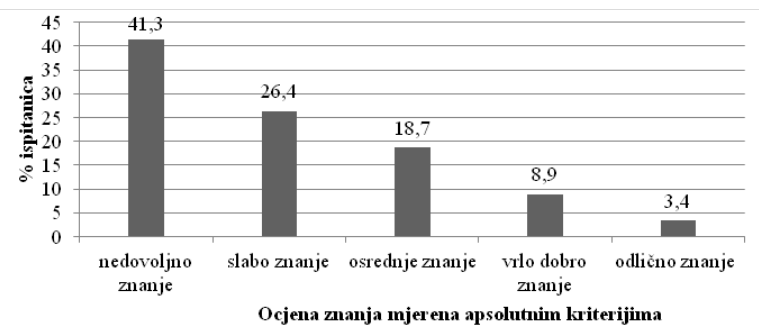

U tablici 1. prikazani su rezultati pojedinačnih pitanja kojima se procjenjivalo znanje pacijentica o informiranom pristanku. Dobro poznavanja propisa pacijentice su pokazale u odnosu na spoznaju zakonske obveze potpisivanja pristanka prije operativnog zahvata $175(74,5 \%)(\mathrm{p}<0,001)$, te su vrlo dobro znale da ukoliko pacijent nije u mogućnosti potpisati pristanak, to može učiniti član uže obitelji $193(82,1 \%)(p<0,001)$. Slabo znanje pacijentice su pokazale u odnosu na spoznaju da su dužne potpisati izjavu o odbijanju, ukoliko odbiju predloženi medicinski zahvat, $153(65,1 \%)(\mathrm{p}<0,001)$. Daleko najlošije znanje pokazale su u odnosu na spoznaju da nisu upoznate s pravom na naknadu $66(28,1 \%)$ $(\mathrm{p}<0,001)$ i s pravom na promjenu mišljenja nakon potpisivanja pristanka, tako je samo $71(30,2 \%)$ ( $\mathrm{p}=0,015)$ znalo da mogu promijeniti svoje mišljenje. Također, su nedovoljno znanje pokazale u odnosu na zakonsku odredbu po kojoj se neće operirati ukoliko odbiju potpisati pristanak, pa čak i ako bi mogli umrijeti, gdje je tako odgovorilo 69 ispitanica $(29,4 \%)(p=0,274)$. 
Tablica 1. Prikaz pojedinačnih pitanja kojima se ispitivalo znanje o informiranom pristanku.

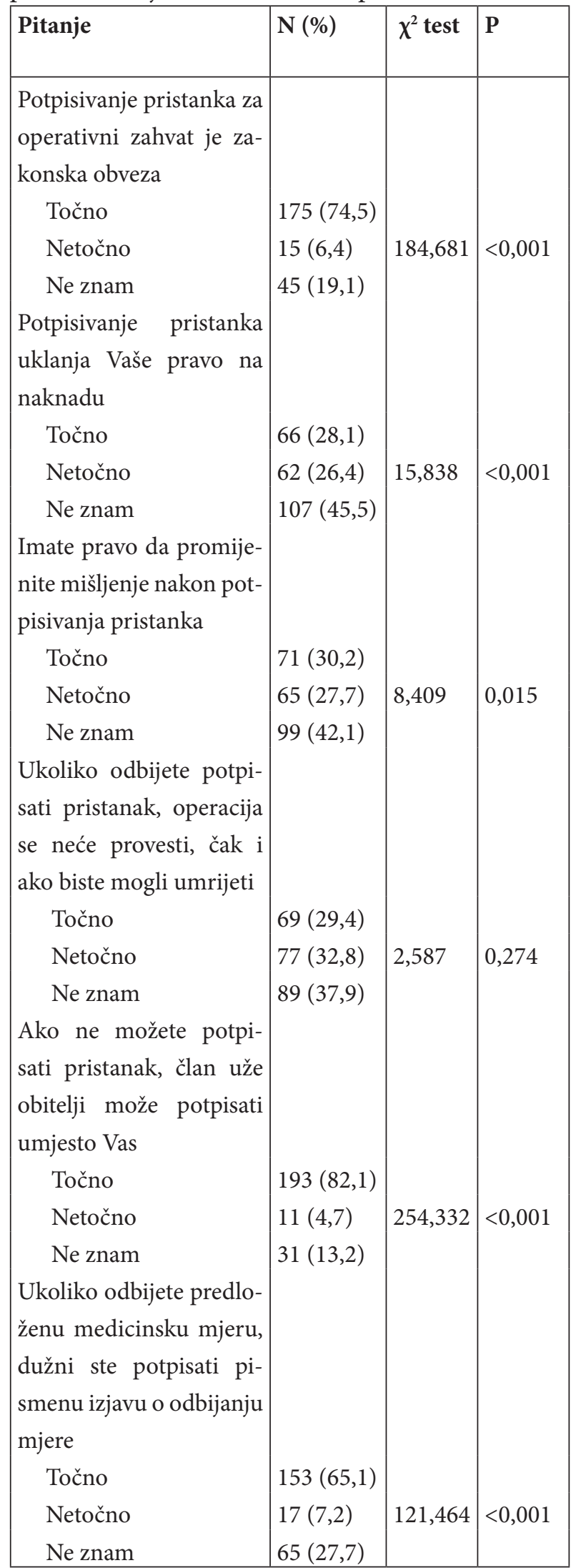

Kao što je vidljivo iz tablice 2 . velika većina je znala da liječnik ne može učiniti ništa drugačije od onoga što je potpisano u obrascu, osim ako to ne služi spašavanju života u smrtnoj opasnosti $207(88,1 \%)(p<0,001)$. Isto tako, pacijentice su uglavnom shvatile što će se dogoditi 207 (88,1 \%) $(\mathrm{p}<0,001)$., bile su svjesne postojanja rizika pri operaciji $222(94,5 \%)(\mathrm{p}<0,001)$ i znale su na što točno pristaju $199(84,7 \%)(\mathrm{p}<0,001)$ (Tablica 2). Tablica 2. Prikaz razumijevanja koncepta informiranog pristanka

\begin{tabular}{|c|c|c|c|}
\hline Pitanje & $\mathrm{N}(\%)$ & $\chi^{2}$ test & $\mathrm{P}$ \\
\hline $\begin{array}{l}\text { Liječnik ne može uči- } \\
\text { niti ništa drugačije od } \\
\text { onoga što je potpisano } \\
\text { u obrascu, osim ako } \\
\text { to ne služi spašavanju } \\
\text { života u smrtnoj opa- } \\
\text { snosti } \\
\text { Točno }\end{array}$ & $207(88,1)$ & & \\
\hline Netočno & $28(11,9)$ & 136,345 & $<0,001$ \\
\hline $\begin{array}{l}\text { Bez odgovora } \\
\text { Shvatila sam što će se } \\
\text { dogoditi } \\
\text { Točno }\end{array}$ & $207(88,1)$ & & \\
\hline Netočno & $28(11,9)$ & 136,345 & $<0,001$ \\
\hline $\begin{array}{l}\text { Bez odgovora } \\
\text { Shvatila da postoje rizi- } \\
\text { ci pri operaciji } \\
\text { Točno }\end{array}$ & $222(94,5)$ & & \\
\hline $\begin{array}{l}\text { Netočno } \\
\text { Bez odgovora }\end{array}$ & $\begin{array}{l}12(5,1) \\
1(0,4)\end{array}$ & 188,462 & $<0,001$ \\
\hline $\begin{array}{l}\text { Nisam sigurna na što } \\
\text { sam točno pristala } \\
\text { Točno }\end{array}$ & $34(14,5)$ & & \\
\hline $\begin{array}{l}\text { Netočno } \\
\text { Bez odgovora }\end{array}$ & $\begin{array}{l}199(84,7) \\
2(0,9)\end{array}$ & 116,845 & $<0,001$ \\
\hline
\end{tabular}




\section{RASPRAVA}

Prema nama dostupnim podacima ovo je prvo istraživanje u Bosni i Hercegovini u kojem su se ispitivala znanja pacijenata o informiranom pristanku za operativni zahvat. Uzimajući u obzir apsolutne kriterije znanja, rezultati ovog istraživanja su pokazali kako dvije trećine pacijentica imaju slabo znanje o informiranom pristanku (10). Slično znanje i nerazumijevanje informiranog pristanka pokazali su i liječnici u Federaciji $\mathrm{BiH}$, samo je 50 \% liječnika točno odgovorilo na sva pitanja o informiranom pristanku (11). Razlozi slabog znanja pacijenata u ovom istraživanju vjerojatno su kasnija implementacija informiranog pristanka u zakonske propise Federacije Bosne i Hercegovine, te samim tim i sporija primjena u praksi. I u drugoj dostupnoj literaturi je nađeno kako pacijenti imaju slabo znanje o informiranom pristanku (12-14). Oni često nisu upoznati s terminom informiranog pristanka, ne znaju svoja prava i ne razumiju proces informiranog pristanka, što rezultira pogrešnim uvjerenjima (15-19). Pacijentice u ovom istraživanju su pokazale vrlo dobro znanje u odnosu na spoznaju o potpisivanju pristanka za operativni zahvat. Većina $(74,5 \%)$ je odgovorila kako je potpisivanje pristanka za operativni zahvat zakonska obveza, što je točno i definirano je zakonskim propisima u Federaciji Bosne i Hercegovine $(5,20)$. Nasuprot tomu, u Velikoj Britaniji po zakonu je valjan usmeni informirani pristanak, a kao dobra praksa preporuča se za kirurške zahvate imati i pismeni pristanak (21). Upozoravajuća činjenica u ovom istraživanju je daleko najslabije iskazano znanje u odnosu na spoznaju da potpisivanje pristanka ne uklanja pravo na naknadu štete. Samo 26,4 \% pacijentica je znalo da potpisani obrazac pristanka ne uklanja pravo na naknadu štete. Istina je da pacijenti često formalno potpisuju obrazac pristanka i smatraju kako se potpisivanjem obrasca bolnica želi zaštiti od mogućih odštetnih zahtjeva pacijenata. Čak i ako se dogodi pogreška veoma rijetko traže svoja prava pred nadležnim institucijama ili pred sudovima. Neki od razloga za ovo su loša informiranost o pravima pacijenta, nepovjerenje u institucije sistema i pravovremeno obeštećenje, mogući visoki troškovi vođenja ovakvih postupaka kao i nepoznavanje zakonskih mehanizama putem kojih mogu zaštiti svoja prava $(22,23)$. U Federaciji Bosne i Hercegovine pristanak na predloženu medicinsku mjeru pacijent može usmeno opozvati sve dok ne započne njeno izvođenje (5). Nešto manje od trećine (30,2 \%) pacijentica iz ovog istraživanja znalo je da mogu promijeniti odluku o medicinskom postupku nakon što su potpisale obrazac pristanka, dok drugi autori navode nešto bolje znanje pacijenata $(2,9,24)$. Prikazani rezultati ističu potrebu za edukacijom zdravstvenih djelatnika ali i pacijenata na nacionalnoj razini kako bi se poboljšala kvaliteta informiranog pristanka. Pitanje informiranog pristanka u praksi postaje interesantno kada pacijent odbije predloženi medicinski postupak. Ponekad se u pitanje dovodi i procjena njegovih mentalnih sposobnosti, a da se pri tom nije pacijent valjano informirao o predloženom medicinskom postupku. Turković ističe kako je pravo na odbijanje medicinskog postupka smo druga strana prava na davanje pristanka i s njime čini jednu cjelinu (4). U ovom istraživanju 65,1\% pacijentica je znalo da trebaju potpisati pisanu izjavu o odbijanju predloženog medicinskog postupka, dok je samo 7,2 \% netočno odgovorilo, ili nije znalo odgovor $(27,7 \%)$. Dosta lošije znanje su pokazali u odnosu na spoznaju obavljanja hitne operacije bez pristanka pacijenta. Samo trećina pacijentica $(32,8$ \%) je točno odgovorila kako pristanak nije potreban u hitnim situacijama, dok rezultati istraživanja kojeg je provela Akkad sa sur. navode točan odgovor u $67 \%$ pacijentica (9). Istražujući sličnosti i razlike u znanjima, stavovima i mišljenju o informiranom pristanku između pacijenata-ovisnika i liječnika medicine, Gazdek je u svom radu iz 2011. utvrdila kako je $54,1 \%$ pacijenata i $72,3 \%$ liječnika točno odgovorilo kako pristanak nije potreban u hitnim medicinskim intervencijama (2). Većina pacijentica $(82,1 \%)$ pokazala je vrlo dobro znanje u odnosu na spoznaju da član uže obitelji ili osoba koju odrede može umjesto njih potpisati pristanak za operativni zahvat u slučaju da osobno postanu nesposobne. U kliničkoj praksi potpisivanje pristanka interesantno je razmotriti s pozicije zaštite pacijenta koji nije sposoban dati pristanak. Posebno je značajno istaći kako bi u medicinskim postupcima ipak trebalo 
u što većoj mjeri uzimati u obzir mišljenje djeteta, osoba s duševnim smetnjama i osoba lišenih poslovne sposobnosti (5). Tijekom operacije može doći do potrebe za proširenjem operativnog zahvata koji se nije mogao pretpostaviti. U nedostatku pacijentovog pristanka prošireni se operativni zahvat može obaviti bez prethodno jasno izraženog dobrovoljnog pristanka, ali uz pretpostavljeni pristanak. Ta mogućnost ograničena je na hitna stanja u kojima je vitalno ugrožen život, potom ako bi nepoduzimanjem ili odlaganjem liječničkog postupka bio ugrožen život pacijenta, ili bi njegovo nepoduzimanje imalo dalje moguće zdravstvene probleme kojima bi se pacijent mogao izložiti, u slučaju nepoduzimanja nekog za njega, u tom trenutku korisnog medicinske postupka što je i u skladu s člankom 9. Bioetičke konvencije $(5,25)$. Velika većina pacijentica $(88,1 \%)$ iz ovog istraživanja vjeruje da liječnik ne može učiniti ništa drugačije od onog što je potpisano u obras$\mathrm{cu}$, osim ako taj postupak služi spašavanju života u smrtnoj opasnosti. Samo 11,9 \% pacijentica potpisivanjem obrasca nije razumjelo što će se događati tijekom operacije, dok su gotovo svi pacijenti $(94,5$ $\%)$ shvatili da postoje rizici pri operaciji. Ako pacijent ne razumije informacije vezane za operativni zahvat koji se nad njim obavlja kvaliteta zdravstvene skrbi je upitna. Brojni su radovi koji navode da pacijenti obično ne osjećaju potrebu za traženjem više informacija, te da je njihovo znanje o prednostima i rizicima medicinskih intervencija slabo (26-30). Nasuprot tomu, pojedini autori pak navode da pacijenti žele mnogo više informacija nego što ih uistinu dobivaju te da potpuno informiranje može biti ograničeno ako se radi o težim bolestima kao što su karcinomi te liječnici neće razotkriti sve informacije (31,32).

Razlike pacijentica u znanju o primjeni informiranog pristanka u kliničkoj praksi prema reproduktivnim čimbenicima nisu bile značajne. Razlike u znanju pacijentica o informiranom pristanku, u odnosu na ispitivana sociodemografska obilježja pacijentica, suviše su mala za bilo kakvo značajno zaključivanje, te bi buduća istraživanja mogla jasnije oslikati koja obilježja pacijentica utječu na bolje poznavanje koncepta informiranog pristanka. Svakako da pristup korišten u ovom istraživanju zahtijeva niz provjera na drugačije odabranim uzorcima. Rezultati ovog istraživanja su ograničeni samo na žene, te bi slično istraživanje s drugim skupinama pacijenata, kao i zdravstvenim djelatnicima bilo poželjno.

\section{ZAKLJUČAK}

U kliničkom radu dobivanje pristanka nije uvijek jednostavno obzirom na činjenicu da pacijenti nisu u dovoljnoj mjeri upoznati sa svojim zakonskim pravima, te se u praksi ne usuđuju u većoj mjeri inzistirati na njihovom ostvarenju. Prikazani rezultati snažno upućuju da na znanje o informiranom pristanku više utječe primjena koja se provodi u praksi negoli zakonski propisane norme. Dokaz tome jest iskazano slabo znanje o pojedinim elementima informiranog pristanka kada se uspoređuje s postojećim zakonskim propisima. Evidentno je kako su pacijentice imale dobro znanje u odnosu na spoznaju da je potpisivanje pristanka za operativni zahvat zakonska obveza. Loše znanje pacijentice su pokazale u odnosu na naknadu štete, mogućnost promjene odluke nakon potpisivanja pristanka, te da je za hitni operativni zahvat potreban pristanak. U konačnici važno je naglasiti kako je temelj moderne medicine obavezni pristanak informiranog pacijenta prije bilo kakvog medicinskog postupka. Stoga je cilj osnažiti znanje pacijenata ali i zdravstvenih djelatnika o informiranom pristanku sustavnim edukacijama i primjenom zakonskih propisa u kliničkoj praksi. 


\section{LITERATURA}

1. Gosić N. Bioetika in vivo. Zagreb: Pergamena; 2005.

2. Gazdek D. Informirani pristanak u liječenju ovisnosti o opijatima [dissertation]. Zagreb: Medicinski fakultet Sveučilišta u Zagrebu; 2011.

3. Turković K. Pravo pacijenta na suodlučivanje prema Zakonu o zaštiti prava pacijenata. U: Bakran I, Ivanišević G. Bolesnik: Prava i obveze. Knjiga izlaganja na V. proljetnom bioetičkom simpoziju Hrvatskog liječničkog zbora. Zagreb: Hrvatski liječnički zbor; 2005.

4. Turković K. Informirani pristanak i pravo na odbijanje medicinskog tretmana u Republici Hrvatskoj. Medicina 2008;44:158-70.

5. Zakon o pravima, obvezama i odgovornostima pacijenata. ("Službene novine Federacije $\mathrm{BiH}$ ", broj 40/10.)

6. Krivični zakon Federacije Bosne i Hercegovine ("Službene novine FBiH", br. 36/03, 37/03, 21/04, 69/04, 18/05, 42/10, 42/11,76/14,46/16 i 75/17.)

7. Jakovljević B, Segedi D, Mujović-Zornić H. Medicinsko-pravni aspekti histerektomije. Novi Sad. Medicinski preglednik. 2007;60:251-54.

8. Perić $\mathrm{O}$, Mišić $M$, Tirić $\mathrm{D}$, Penava N, Bušić $\mathrm{D}$, Tomić V. Iskustvo pacijentica informiranim pristankom kod planiranih i hitnih operativnih zahvata. Zenica. Medicinski glasnik. 2018;15 (2):179-185.

9. Akkad A, Jackson C, Kenyon S, Dixon-Woods M, Taub N, Marwan H. Patients 'perceptions of written consent: questionnaire study. BMJ. 2006;333 (7567):528.

10. Vujević M. Uvođenje u znanstveni rad u području društvenih znanosti. VI dopunjeno izdanje. Zagreb: Školska Knjiga;2002.

11. Nikšić D. Ispitivanje stava doktora medicine o potrebi informiranog pristanka u Federaciji Bosne i Hercegovine. Sarajevo: Medicinski fakultet Univerziteta u Sarajevu, Katedra za socijalnu medicinu i organizaciju zdravstvene zaštite sa historijom medicine;2009.
12. Mulsow JJ, Feeley TM, Tierney S. Beyond consent--improving understanding in surgical patients. Am J Surg.2012;203:112-20.

13. Schenker Y, Fernandez A, Sudore R, Schillinger D. Interventions to improve patient comprehension in informed consent for medical and surgical procedures: a systematic review. Med Decis Making 2011;31:151-73.

14. Nemcekova M, Ziakova K, Mistuna D, Kudlicka J. Respecting patients' rights. Bull Med Ethics. 1998;140:13-8.

15. Vučemilo L, Milošević M, Babić-Bosanac S, Mustajbegović J, Borovečki A. Is there a need to improve the informed consent procedures in Croatia - a pilot field survey on a representative sample, a food for thought? Rev Rom Bioet 2014;12:25-33.

16. Krizova E, Simek J. Theory and practice of informed consent in the Czech Republic. J Med Ethics. 2007;33:273-7.

17. Schouten B, Hoogstratens J, Eijkman M. Dutch dental patients on informed consent: attitudes, self-efficacy and behavior. Patient Educ Couns. 2002;46:47-4.

18. Billclife N, McCabe E, Brown KW. Informed consent to medication in longterm Psychiatric in-Patients. Psychiatr Bull. 2001;25:132-4.

19. Kusec S, Oreskovic S, Skegro M, Korolija D, Busic Z, Horzic M. Improving comprehension .of informed consent. Patient Educ Couns. 2006;60:294-300.

20. Zakon o zdravstvenoj zaštiti. ("Službene novine Federacije BiH", broj 28/97.)

21. Department of Health (DH). Reference guide to consent for examination or treatment, second edition 2009. London; DH;2009. [Internet] [preuzeto 10.ožujka 2012]. Dostupno na: www. dh.gov.uk/consent

22. Rušinović-Sunara $Đ$, Babič-Bosanac S, Vučemilo L. Prava pacijenata - raskrižje bez jasnog putokaza? U: Šogorić S, Štimac D, ur. Knjiga sažetaka. Drugi hrvatski kongres preventivne medicine i unapređenja zdravlja. Zagreb; 2010. $261 \mathrm{p}$. 
23. Klarić P. Odštetna odgovornost medicinskih ustanova i liječnika, Odgovornost za štetu. Pravo u gospodarstvu. 2001;40:47-86.

24. Dawes PJD, Davison P. Informed consent: What do patient want to know? JR Soc Med. 1994;87:149-52.

25. Vladavina prava. Konvencija o zaštiti ljudskih prava i dostojanstva ljudskih bića glede primjene biologije i medicine: Konvencija o ljudskim pravima i biomedicini. Zagreb. 1998;3-4:151-72.

26. Abolfotouh MA, Adlan AA. Quality of informed consent for invasive procedures in central Saudi Arabia. Int J Gen Med. 2012;5:269-75.

27. Sahin N, Ozturk A, Ozkan Y, Demirhan Erdemir A. What do patients recall from informed consent given before orthopedic surgery? Acta Orthop Traumatol Turc. 2010;44:469-75.

28. Crepeau AE, McKinney BI, Fox-Ryvicker M, Castelli J, Wang ED. Prospective evluation of patient comprehension of informed consent. J Bone Joint Surg Am. 2011;93:114.
29. Brezis M, Israel S, Weinstein-Birenshtock A, Pogoda P, Sharon A, Tauber R. Quality of informed consent for invasive procedures. Int J Qual Health Care. 2008;20(5):352-7.

30. Vučemilo L, Curković M, Milošević M, Mustajbegović J, Borovečki A. Are physicianpatient communication practices slowly changing in Croatia? - a cross-sectional questionnaire study. Croat Med J. 2013;54(2):185-91

31. Jackson GN, Robinson PN, Lucas DN, Natarajan A, Gough K, Woolnough M, Yentis SM.What mothers know, and want to know, about the complications of general anaesthesia. Acta Anaesthesiol Scand. 2012;56:585-8.

32. Yousuf RM, Fauzy ARM, How SH, Rasool AG, Rehana K. Awareness, knowledge and attitude towars informed consent among doctors in two different cultures in Asia: a cross-sectional comparative study in Malaysia and Kashmir, India. Singapore Med J.2007;48:559-65. 


\title{
ETHICAL AND LEGAL KNOWLEDGE OF GYNAECOLOGICAL PATIENTS ON INFORMED CONSENT IN SURGERY INTERVENTIONS
}

\author{
Olivera Perićl, Vajdana Tomić1, Dejan Tirić1 ${ }^{1}$ IvonaMargeta ${ }^{2}$ \\ ${ }^{1}$ Department of Gynecology and Obstetrics, University Clinical Hospital Mostar, 88000 Mostar, Bosnia \& \\ Herzegovina \\ ${ }^{2}$ Transfusion center, University Clinical Hospital Mostar, 88000 Mostar, Bosnia \& Herzegovina
}

\begin{abstract}
INTRODUCTION: In the Federation of Bosnia and Herzegovina,informed consent in surgery interventions is an ethical postulate and a legal obligation defined by legal regulations.

OBJECTIVE:The main objective of this study was to assess the knowledge of gynecological patients on informed consent in surgery interventions and determine whether there are any differences in the knowledge on informed consent of gynecological patients and socio-demographic and gynecological-obstetric characteristics.

SUBJECTS AND METHODS:The study included 235 patients who had surgery at the Department of Gynecology and Obstetrics of the University Clinical Hospital Mostar. The study was conducted with an anonymous questionnaire specially designed for this purpose. The study was conducted according to the degree of emergency, the patients were divided into two groups, patients with planned surgical procedures $(\mathrm{n}=154)$ and patients with urgent surgical procedures $(\mathrm{n}=90)$. RESULTS: All patients were adults ranging from 18 to 86 years, and the average patient age was 34 years. The patients showed good knowledge in relation to the findings that written consent is defined by law $(74.5 \%)$ and that consent can be signed by an immediate family member ( $82.1 \%)$. The patients had poor knowledge of their obligation to sign a refusal statement if they reject the proposed medical procedure (65.1\%). The patients showed insufficient knowledgeof the right to compensation (28.1\%), the right to change an opinion after signing the consent $(30.2 \%)$ and that surgery will not be performed if they do not sign the consent,even in life threating situations (29.4\%).

CONCLUSION:The patients have poor knowledge of the right to informed consent which indicates that the process of consent is a mere formality.
\end{abstract}

Key words: written consent, planned surgery, emergency surgery

Correspondence: Olivera Perić,

Email: olivera.peric@yahoo.com, olivera.peric@fzs.sum.ba 